\title{
Counseling Leaflet Methods And Social Media To Change Knowledge Of Pregnant Women In The Third Trimester At Salassae Health Center
}

\author{
Asmirati $^{1}$, Marwidah $^{2}$, Mitra Asriani ${ }^{3}$, Irmawati $^{4}$ \\ ${ }^{I}$ Departement of Midwife, Stikes Panrita Husada Bulukumba, Indonesia \\ ${ }^{2}$ Departement of Midwife, Stikes Panrita Husada Bulukumba, Indonesia \\ ${ }^{3}$ Departement of Midwife, Stikes Panrita Husada Bulukumba, Indonesia \\ ${ }^{4}$ Departement of Midwife, Stikes Panrita Husada Bulukumba, Indonesia
}

Corresponding author: Mitra Asriani

Email: mitra.asrianiamin@gmail.com

\begin{abstract}
ABSTRAC
Family planning is an example of direct policy in the field of population control. Strategic intervention in safe motherhood efforts is expressed as 4 pillars namely family planning, antenatal care, clean and safe delivery, and essential obstetric services. The development of new media based on the internet has greatly influenced media consumption patterns in Indonesian society. The study used experimental quasi research designs with group pre-test and post-test designs. It used 100 respondents as selected samples using Purposive Sampling. The results of the statistical signed rank test were obtained on average the knowledge of respondents before being given intervention with a leaflet of 9.76 while after being given intervention 16.34 with $\mathrm{P}$ value (Asymp). Sig. (2-tailed)) 0,000 where $<0.05$ so that it can be concluded that there are significant differences before and after respondents are given intervention with leaflets. The average value before being given intervention in the form of social media Whatsaap amounted to 8.54 while after being given an average value of 17.72 with an average value of 17.72 with $P$ value (Asymp). Sig. (2-tailed)). Based on the results of the wilcoxon statistics test sum rank test or commonly called Mann-whitney u test obtained a mean leaflet value of 35.85 while whatsapp social media amounted to 65.15 with a $\mathrm{p}$ value of 0.00 . This proves that whatsapp social media has a greater influence in increasing knowledge compared to leaflet media.
\end{abstract}

Kyword : Leaflet; Whatsapp; Knowledge of Pregnant Women 


\section{PENDAHULUAN}

Keluarga berencana merupakan contoh kebijakan langsung dibidang pengendalian penduduk. Intervensi strategis dalam upaya safe motherhood dinyatakan sebagai 4 pilar yaitu keluarga berencana, asuhan antenatal, persalinan bersih dan aman, dan pelayanan obstetrik esensial. Program keluarga berencana sebagai pilar pertama dianggap telah berhasil. Namun, untuk mendukung upaya mempercepat penurunan AKI, diperlukan penajaman sasaran agar kejadian "4 terlalu" dan kehamilan tidak diinginkan dapat ditekan serendah mungkin. Salah satu pendekatan program yang berhubungan adalah program KB pasca persalinan, karena KB pasca persalinan dilakukan pada masa nifas, sehingga perencanaan kehamilan yang aman dan sehat dapat segera diatur (Saifuddin, 2009 dalam Khotimah, 2015).

Konseling $\mathrm{KB}$ postpartum berpengaruh terhadap penggunaan kontrasepsi pasca persalinan (Akman et al, 2010 dalam Khotimah, 2015). Beberapa penelitian menunjukkan bahwa ada peningkatan signifikan dalam penggunaan metode kontrasepsi efektif pada wanita melalui penyediaan leaflet dan konseling (Saeed et al, 2008 dalam Khotimah, 2015). Konseling merupakan salah satu cara pemberian informasi kesehatan yang efektif dengan komunikasi Edukasi (KIE) dua arah yang dilakukan oleh seorang konselor tenaga kesehatan kepada pasien dan konselor juga dapat menerima atau mendengar keluhan atau pendapat dari pasien (Liliweri, 2011). Konseling saat ini juga dilakukan dengan menggunakan (memanfaatkan) berbagai jenis media untuk menyampaikan Informasi, dan dsalah satuyang sedang booming saat ini adalah pemanfaatan media internet.

Masyarakat saat ini tidak hanya diterpa informasi melalui media televisi, koran, radio saja. Perkembangan media baru yang berbasis pada internet telah sangat memengaruhi pola konsumsi media pada masyarakat Indonesia. Ledakan pengguna internet sebagai "ruang" untuk membangun relationship dapat dilihat berdasarkan jumlah pengguna internet di Asia pada akhir tahun 2013. Indonesia masuk dalam top 5 besar pengguna internet di Asia dengan jumlah 71,2 juta users dibawah China, India, Jepang, dan diatas Korea Selatan (Kurniasari, 2016).

Adanya media baru yang bisa dimanfaatkan inilah maka penulis tertarik untuk meneliti mengenai pengaruh pemberian konseling metode leaflet dan media sosial terhadap perubahan pengetahuan ibu hamil trimester III tentang alat kontrasepsi pasca salin di puskesmas salassae tahun 2020. 


\section{METODE PENELITIAN}

\section{Desain Penelitian}

Penelitian ini telah dilaksanakan di wilayah kerja UPT Puskesmas Tanete dan UPT Puskesmas Salassae Kecamatan Bulukumpa Kabupaten Bulukumba. Tempat ini dipilih karena wilayah ini dilalui oleh jalan provinsi sehingga jaringan telpon seluler dan internet sangat lancar. Penelitian ini menggunakan desain penelitian quasi eksperimental dengan rancangan pre-test dan post-test grup.

\section{Populasi dan sampel}

Populasi dalam penelitian ini adalah seluruh ibu hamil yang ada di wilayah kerja UPT Puskesmas Tanete dan UPT Puskesmas Salassae Kecamatan Bulukumpa Kabupaten Bulukumba. Teknik sampling yang digunakan dalam penelitian ini adalah menggunakan Purposive Sampling dengan kriteria inklusi Ibu hamil primipara yang bersedia menjadi responden, Kondisi ibu normal, kehamilan normal ,Ibu dapat berkomunikasi dengan baik, Ibu bisa membaca dan menulis, Ibu bisa menggunakan smartphone dan aplikasi media sosial.

\section{Metode pengumpulan data}

Sampel dikumpulkan oleh peneliti kemudian diberikan kuisioner yang berisi 20 pertanyaan seputar Alat kontrasepsi pasca salin untuk mengukur pengetahuan responden. Setelah data pretest didapatkan sampel kemudian diberi intervensi. 50 responden di beri intervensi dengan menggunakan leafleet dan 50 lainnya dengan menggunakan media sosial. Setelah intervensi dilakukan sampel kemudian kembali diberi kuisioner untuk mendapatkan data posttest

\section{Analisis data}

Setelah data pre-test dan post-test yang didapatkan akan diolah dengan rumus uji wilcoxon signed rank test untuk mengetahui perubahan pengetahuan sebelum dan sesudah diberi intervensi. Sedangkan untuk membandingakan kedua media yang digunakan pada kedua kelompok yang diintervensi digunakan uji wilcoxon sum rank test.

\section{HASIL}

Berdasarkan Tabel 1 diatas menunjukkan dari 100 orang responden, terbanyak dengan usia antara 20-29 yaitu 75 orang (75\%), mayoritas responden bekerja sebagai ibu rumah tangga yaitu 75 orang (75\%), sementara untuk tingkat pendidikan responden yang paling banyak berpendidikan SMA yaitu 63 orang(63\%). 
Tabel 1. Karakteristik sampel penelitian

\begin{tabular}{|c|c|c|}
\hline Karakteristik & Frekuensi (n) & Persentase $(\%)$ \\
\hline \multicolumn{3}{|l|}{ Umur } \\
\hline$<20$ & 15 & $15 \%$ \\
\hline $20-29$ & 75 & $75 \%$ \\
\hline$>30$ & 10 & $10 \%$ \\
\hline Total & 100 & 100 \\
\hline \multicolumn{3}{|l|}{ Pekerjaan } \\
\hline Bekerja & 25 & $25 \%$ \\
\hline Tidak bekerja & 75 & $75 \%$ \\
\hline Total & 100 & 100 \\
\hline \multicolumn{3}{|l|}{ Tingkat Pendidikan } \\
\hline SD & 15 & $15 \%$ \\
\hline SMP & 10 & $10 \%$ \\
\hline SMA & 65 & $65 \%$ \\
\hline $\mathrm{S} 1$ & 10 & $10 \%$ \\
\hline Total & 100 & 100 \\
\hline
\end{tabular}

Berdasarkan pada tabel 2 menunjukkan perubahan pengetahuan sebelum dan sesudah diberikan intervensi berupa leaflet. Hasil uji statistic signed rank test didapatkan rerata pengetahuan responden sebelum diberikan intervensi dengan leaflet sebesar 9,76 sedangkan setelah diberikan intervensi 16,34 dengan P value (Asymp. Sig. (2-tailed)) 0,000 dimana $<0,05$ sehingga bisa ditarik kesimpulan bahwa ada perbedaan bermakna sebelum dan sesudah responden diberikan intervensi dengan Leaflet.

Tabel 2. Perubahan pengetahuan sebelum dan sesudah diberikan intervensi leaflet

\begin{tabular}{lccc}
\hline & & Test Statistics $^{\text {b }}$ & \\
\hline & Pengetahuan & Mean \pm SD & P Value \\
\hline Pretest & $9,76 \pm 2,79$ & 0,000 \\
Postest & $16,34 \pm 1,205$ & \\
\hline
\end{tabular}

Pada tabel 3 menunjukkan perubahan pengetahuan sebelum dan sesudah diberi intervensi berupa leaflet. Hasil uji statistic signed rank test didapatkan nilai rerata sebelum diberi intervensi berupa media sosial Whatsaap sebesar 8,54 sedangkan setelah diberi intervensi nilai rerata sebesar 17,72 dengan P value (Asymp. Sig. (2-tailed)) 0,000 dimana <0,05 sehingga bisa ditarik kesimpulan bahwa ada perbedaan bermakna sebelum dan sesudah responden diberikan intervensi dengan media sosial Whatsaap. 
Tabel 3. Perubahan pengetahuan sebelum dan sesudah diberikan intervensi dengan media sosial Whatsapp

\begin{tabular}{ccc} 
& \multicolumn{2}{c}{ Test Statistics $^{\mathbf{b}}$} \\
\hline Pengetahuan & Mean \pm SD & P \\
\hline Pretest & $8,54 \pm 2,77$ & 0,000 \\
Postest & $17,72 \pm 1,088$ & \\
\hline
\end{tabular}

Tabel 4 menunjukkan perbandingan dari kedua media yang digunakan yaitu leaflet dan media sosial Whatsaap. Berdasarkan hasil uji statistic Wilcoxon sum rank test atau biasa disebut dengan Mann-whitney u test didapatkan nilai mean leaflet sebesar 35,85 sedangkan media sosial whatsapp sebesar 65,15 dengan nilai $p$ value sebesar 0,00 . Hal ini membuktikan bahwa media sosial whatsapp memiliki pengaruh yang lebih besar dalam peningkatan pengetahuan dibandingkan dengan media leaflet.

\section{Tabel 4.Perbandingan media leaflet dan media sosial whatsapp}

\begin{tabular}{ccc} 
& Test Statistics $^{\mathbf{b}}$ & \\
\hline Media & Mean & P value \\
\hline Leaflet & 35,85 & 0,00 \\
Whatsaap & 65,15 & \\
\hline
\end{tabular}

\section{PEMBAHASAN}

Hasil uji statistic signed rank test didapatkan rerata pengetahuan responden sebelum diberikan intervensi dengan leaflet sebesar 9,76 sedangkan setelah diberikan intervensi 16,34 dengan P value (Asymp. Sig. (2-tailed)) 0,000 dimana <0,05 sehingga bisa ditarik kesimpulan bahwa ada perbedaan bermakna sebelum dan sesudah responden diberikan intervensi dengan Leaflet.

Menurut Notoatmodjo (2003) media berperan dalam peningkatan pengetahuan. Fungsi media dalam pendidikan adalah sebagai alat peraga untuk menyampaikan informasi atau pesan- pesan tentang kesehatan. Dalam hal ini media leaflet disebut sebagai media statis cetak yang terlipat dan mengutamakan pesan-pesan visual. Media leaflet terdiri dari gambaran sejumlah kata, gambar atau foto dalam tata warna. Kelebihan media leaflet dibandingkan media lainnya adalah tahan lama,tidak memerlukan listrik, serta mampu mencakup banyak orang (Aryana and Suyasa, 2012; Bertalina, 2015).

Hasil uji statistic signed rank test didapatkan nilai rerata sebelum diberi intervensi berupa media sosial Whatsaap sebesar 8,54 sedangkan setelah diberi intervensi nilai rerata sebesar 17,72 dengan $\mathrm{P}$ value (Asymp. Sig. (2-tailed)) 0,000 dimana $<0,05$ sehingga bisa ditarik 
kesimpulan bahwa ada perbedaan bermakna sebelum dan sesudah responden diberikan intervensi dengan media sosial Whatsaap.

Hasil penelitian ini juga sejalan dengan penelitian yang dilakukan oleh Elies Meilinawati Sri Budihartini yang berjudul "Pemilihan Metode Kontrasepsi Pada Ibu Pasca Bersalin Berdasarkan Media Informasi yang Digunakan Dalam Konseling” dimana hasil penelitiannya menyatakan bahwa Pemilihan kontrasepsi MKJP lebih besar pada media video dengan kata lain media video lebih efektif dalam menentukan pemilihan kontrasepsi MKJP daripada media leaflet. Media video menggunakan efek suara dan gambar bergerak yang dapat menampilkan langkah-langkah yang terarah, sehingga memudahkan menerima informasi yang disampaikan (Elies Meilinawati Sri Budihartini 2015).

Berdasarkan hasil uji statistic Wilcoxon sum rank test atau biasa disebut dengan Mannwhitney u test didapatkan nilai mean leaflet sebesar 35,85 sedangkan media sosial whatsapp sebesar 65,15 dengan nilai p value sebesar 0,00. Hal ini membuktikan bahwa media sosial whatsapp memiliki pengaruh yang lebih besar dalam peningkatan pengetahuan dibandingkan dengan media leaflet. Metode media sosial whatsaap sangat efektif karena dengan media ini orang-orang akan lebih mudah berkomunikasi, bisa mendapatkan informasi dimana saja dan kapan saja serta bisa mencari berbagai macam referensi melalui media internet. Sedangkan dengan media leaflet informasi yang bisa dimuat sangat terbatas dan tidak semua materi bisa divisualisasikan dan leaflet juga dapat membuat orang cepat bosan.

Media sosial whatsaap dikatakan lebih efektif juga disebabkan karena responden dengan leluasa dapat berkomunikasi dengan peneliti maupun dengan anggota grup whatsaap lainnya sehingga proses pertukaran informasi menjadi lebih mudah dan cepat. Pada media leaflet komunikasi hanya terjadi sangat terbatas hanya antara responden dan peneliti saja. Hal ini sejalan dengan pendapat sizraseni, 2017 yang menyatakan bahwa media sosial merupakan media yang didesain untuk memudahkan interaksi sosial yang bersifat interaktif dengan berbasis teknologi internet yang mengubah pola penyebaran informasi dari sebelumnya bersifat satu kebanyak audiens tetapi sekarang dari banyak audiens ke banyak audiens sehingga lebih memudahkan informasi tersebar dengan cepat dan bebas (Kamariah Hayat, 2017; Sizraseni, 2017).

\section{KESIMPULAN DAN SARAN}

Dari penelitian ini dapat disimpulkan bahwa promosi kesehatan dengan menggunakan whatsapp bisa meningkatkan pengetahuan ibu, terutama dengan keunggulam whatsapp yang memiliki berbagai fitur-fitur yang menarik menjadikannya lebih efektif dibandingkan dengan 
media lain. Dengan adanya media - media baru yang bisa digunakan sebagai sarana promosi kesehatan diharapkan agar pemerintah dan juga petugas kesehatan lainnya lebih gencar melakukan promosi kesehatan dengan kreativ dan inovatif dengan memanfaatkan mediamedia informasi yang semakin maju.

\section{DAFTAR PUSTAKA}

BKKBN. Kebijakan Pengendalian Penduduk, Keluarga Berencana dan Pembangunan Keluarga. BKKBN; 2014.

Elisabeth. (2015). asuhan kebidanan persalinan \& bayi baru lahir. yogyakarta: PT. PUSTAKA BARU.

Elies Meilinawati Sri Budihartini dkk. (2015). Pemilihan Metode Kontrasepsi Pada Ibu Pasca Bersalin Berdasarkan Media Informasi yang Digunakan Dalam Konseling. Jurnal Keperawatan dan Kebidanan STIKes Bina Sehat PPNI Kabupaten Mojokerto. ISSN : 2621-0231

Husin Farid, d. i. (2015). jakarta: sagung setno.

Kamariah Hayat, A. (2017) 'Perbedaan efektivitas pendidikan kesehatan tatap muka dengan media sosial terhadap peningkatan pengetahuan keluarga skizofrenia'.

kumalasari. (2015). salemba medika. jakarta: perawatan antenatal, intranatal, post natal bayi baru lahir, dan kontrasepsi.

Khotimah, V.K. Pengaruh konseling KB pada ibu trimester III terhadap keikutsertaan KB pasca persalinan.di kecamatan sukowono kabupaten jember, Jember : Jurnal Kesehatan Masyarakat; 2015.

Kurniasari, andra fatma (2016) 'Pengaruh Terpaan Iklan Layanan Masyarakat, Penggunaan Media Sosial Facebook, Dukungan Keluarga, Dukungan Lingkungan Kerja Terhadap Tingkat Keberhasilan Ibu Bekerja Memberi Asi Eksklusife', 5(2), pp. 146-158.

Manuaba, (2018) Asuhan Kebidanan Penyakit Kandungan dan KB untuk Pendidkan Bidan, Jakarta : EGC

Manuaba, (2017) Kapita Salekta Penatalaksanaan Rutin Obstebtri Ginekologi dan KB, Jakarta : EGC

Mohctar, (2015) Asuhan Kebidanan Persalinan, Jakarta : EGC

Nining Kurnia1Dkk.(2014). Pengetahuan Ibu Hamil Trimester III Tentang KB Pasca Persalinan di Puskesmas Jetis Kota, Yogyakarta. Jurnal Ners dan Kebidanan Indonesia. Sekolah Tinggi Ilmu Kesehatan Alma Ata Yogyakarta. ISSN2354-7642.

Notoatmodjo, S. (2013) Metode Penetilitian Kuantitatif. Jakarta: ECG.

Prawirohardjo, s. (2018). ilmu kebidanan. jakarta: p.t Bina pustaka sarwono prawirohardjo.

Saifuddin, P. d. (2014). Ilmu Kebidanan Sarwono Prawirohardjo. Jakarta: PT Bina Pustaka Sarwono Prawirohardjo.

Suhertusi, B. and Nurjasmi, E. (2015) 'Pengaruh Media Promosi Kesehatan tentang ASI Eksklusif terhadap Peningkatan Pengetahuan Ibu di Wilayah Kerja Puskesmas Lubuk Begalung Padang Tahun 2014', Jurnal Kesehatan Andalas, 4(1), pp. 17-22.

Sizraseni (2017) 'Hubungan Penggunaan Media Sosial Dengan Interaksi Sosial Mahasiswa Jurusan Bimbingan Konseling Tahun 2016/2017 Iain Batusangkar Sisrazeni'.

Sugiyono.(2011). Metode Penelitian Kuantitatif,Kualitatif dan $R \& D$. Bandung:Afabeta

Sarwono, Prawirohardjo, (2019) Ilmu Kebidanan, Jakarta : Bina Pustaka

Sulistiawati, (2018) Asuhan Kebidanan Pada Ibu Hamil, Jakarta : Penerbit Salemba Medika

Sizraseni (2017) 'Hubungan Penggunaan Media Sosial Dengan Interaksi Sosial Mahasiswa Jurusan Bimbingan Konseling Tahun 2016/2017 IAIN Batusangkar Sisrazeni'.

Sulistiawati, (2018) Asuhan Kebidanan Pada Ibu Hamil, Jakarta : Penerbit Salemba Medika 


\section{Volume 5, Nomor 2, Agustus 2021 \\ JURNAL LIFE BIRTH}

p-ISSN: 2580-0574 ; e-ISSN: 2722-0923

Widyastuti, L. Postpartum Contraceptive Use in Indonesia : Recent Pattems and Determinants. International Conference on Reproductive Health and Social Science Research. 2010. 